\title{
Manipulation of Non-canonical NF-KB Signaling by Non-oncogenic Viruses
}

\author{
Justyna Struzik $^{1}$ (1) - Lidia Szulc-Dąbrowska ${ }^{1}$
}

Received: 22 March 2018 / Accepted: 19 June 2018 / Published online: 8 September 2018

(c) The Author(s) 2018

\begin{abstract}

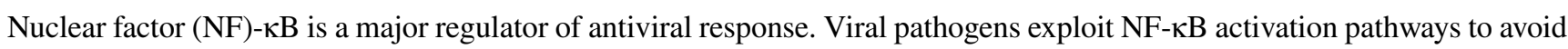
cellular mechanisms that eliminate the infection. Canonical (classical) NF- $\mathrm{kB}$ signaling, which regulates innate immune response, cell survival and inflammation, is often manipulated by viral pathogens that can counteract antiviral response. Oncogenic viruses can modulate not only canonical, but also non-canonical (alternative) NF- $\kappa$ B activation pathways. The non-canonical NF- $\mathrm{KB}$ signaling is responsible for adaptive immunity and plays a role in lymphoid organogenesis, B cell development, as well as bone metabolism. Thus, non-canonical NF- $\mathrm{kB}$ activation has been linked to lymphoid malignancies. However, some data strongly suggest that the non-canonical NF- $\mathrm{kB}$ activation pathway may also function in innate immunity and is modulated by certain non-oncogenic viruses. Collectively, these findings show the importance of studying the impact of different groups of viral pathogens on alternative NF- $\mathrm{KB}$ activation. This mini-review focuses on the influence of non-oncogenic viruses on the components of non-canonical NF-kB signaling.
\end{abstract}

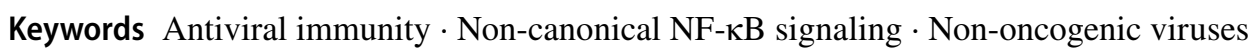

\section{Introduction}

The activation of host antiviral defense mechanisms relies on the subset of transcription factors that regulate innate immune response against pathogens, leading to the transcription of genes encoding molecules that help establish antiviral state (Olagnier and Hiscott 2012). Among transcription regulators of innate antiviral immune response, nuclear factor (NF)- $\mathrm{\kappa B} / \mathrm{p} 65$ and interferon regulatory factor (IRF) 3 act as primary drivers of transcription in response to viral infection. These antiviral factors are controlled by host ubiquitin systems and translocate from the cytoplasm to nucleus in response to external stimuli, such as virus infection. Nuclear translocation of antiviral factors serves the subsequent regulation of transcription of genes involved in immunity and inflammation (Freaney et al. 2013; Rajsbaum and García-Sastre 2013).

Justyna Struzik

justyna_struzik@sggw.pl

1 Division of Immunology, Department of Preclinical Sciences, Faculty of Veterinary Medicine, Warsaw University of Life Sciences-SGGW, Ciszewskiego 8, 02-786 Warsaw, Poland
Proinflammatory cytokines [e.g., tumor necrosis factor (TNF)- $\alpha$, interleukin (IL)-1 $]$ ], B and T cell receptors, as well as viral and bacterial components binding Toll-like receptors (TLRs), induce canonical (classical) NF- $\mathrm{KB}$ signaling cascades (Dejardin 2006; Espinosa et al. 2011; Lawrence 2009). Upon canonical NF-KB stimulation, TNF receptor (TNFR)-associated factor (TRAF) adaptor proteins undergo ubiquitination. Afterwards, transforming growth factor- $\beta$ activated kinase 1 activates the inhibitor $\kappa \mathrm{B}$ (IкB) kinase complex (IKK) composed of IKK $\alpha$, IKK $\beta$ and IKK $\gamma / \mathrm{NF}-\kappa \mathrm{B}$ essential modulator (NEMO) subunits. IKK, in turn, induces $\mathrm{I} \kappa \mathrm{B}$ phosphorylation and its subsequent proteasomal degradation, leading to a rapid release of NF- $\mathrm{\kappa B}$ dimers, including $\mathrm{p} 65 / \mathrm{p} 50$, which then translocate to the nucleus and activate the transcription of immune and inflammatory genes. In general, canonical NF- $\kappa B$ is independent of protein synthesis and has diverse functions (Hayden and Ghosh 2012; Sun 2011).

The non-canonical (alternative) NF- $\mathrm{kB}$ activation pathway requires certain TNFR superfamily receptors, such as TNFR2, lymphotoxin- $\beta$ receptor (LT- $\beta$ R), B cell activating factor receptor (BAFFR), receptor activator of NF- $\kappa \mathrm{B}$ (RANK), CD40, and Fn14. LT- $\beta$ R is expressed in lymphoid stromal and epithelial cells, and BAFFR - mainly in B cells, 
whereas CD40 is attributed to different types of cells, such as dendritic cells (DCs), monocytes, B cells, endothelial and epithelial cells, as well as neurons. RANK receptors, in turn, can be found on osteoclast precursors, DCs and activated B cells (Sun 2011, 2012).

Non-canonical NF- $\kappa \mathrm{B}$ receptors bind TRAF2 and TRAF3, which are subsequently degraded. TRAF degradation is critical for the activation of NF- $\mathrm{KB}$-inducing kinase (NIK) and IKK $\alpha$ kinase. Importantly, NIK, which links IKK $\alpha$ and $p 100$, is an IKK $\alpha$ activating kinase. Both IKK $\alpha$ and NIK induce selective p100 (Ser866 and Ser870) phosphorylation, which leads to the recruitment of ubiquitin ligase composed of Skp1, Cullin-1 and F-box (Skp-Cullin-F-box, SCF). SCF-mediated processing of RelB-associated NF- $\kappa$ B2 p100 to p52, a central step during non-canonical NF- $\mathrm{KB}$ signaling, results predominantly in the activation of p52/RelB complexes (Sun 2011, 2012) (Fig. 1). Unlike the canonical NF- $\mathrm{KB}$ activation pathway, the slow and persistent non-canonical NF-кB activation pathway depends on protein synthesis.

Non-canonical NF- $\mathrm{KB}$ signaling is responsible for specific functions, including lymphoid organogenesis, DC activation, maturation and survival of B cells, as well as bone metabolism (Biswas and Lewis 2010; Dejardin 2006; Espinosa et al. 2011; Hayden and Ghosh 2012; Hoesel and Schmid 2013; Oeckinghaus and Ghosh 2009; Sun 2011). Deregulation of the non-canonical NF- $\mathrm{KB}$ activation results in inflammation, autoimmunity, osteoporosis and lymphoid malignancies (Sun 2011).

Canonical and non-canonical NF- $\kappa \mathrm{B}$ activation pathways are connected via many crosstalk mechanisms (Shih et al. 2011). Canonical NF- $\mathrm{KB}$ signaling activators, such as TNF- $\alpha$, lipopolysaccharide (LPS), interferon (IFN)- $\gamma$, or 12- $O$-tetradecanoylphorbol-13-acetate (TPA), may stimulate the non-canonical NF- $\kappa B$ activation pathway (Kim et al. 2011). Other studies have demonstrated the involvement of LT- $\beta$
Fig. 1 Non-canonical NF- $\kappa \mathrm{B}$ activation pathway. In unstimulated cells, NIK kinase is constitutively degraded by cIAP $1 / 2$ TRAF2-TRAF3 E3 ubiquitin (Ub) ligase complex. Upon receptor stimulation, TRAF3 undergoes degradation via the activity TRAF 2 and cIAP1/2. Thus, NIK is stabilized and accumulates into the cytoplasm. NIK, in turn, activates IKK $\alpha$ kinase. Both NIK and IKK $\alpha$ trigger RelB-associated p100 precursor protein phosphorylation and its subsequent proteasomal processing to active $\mathrm{p} 52$ subunit. As a result, RelB/p52 heterodimers translocate to the nucleus to regulate transcription of target genes

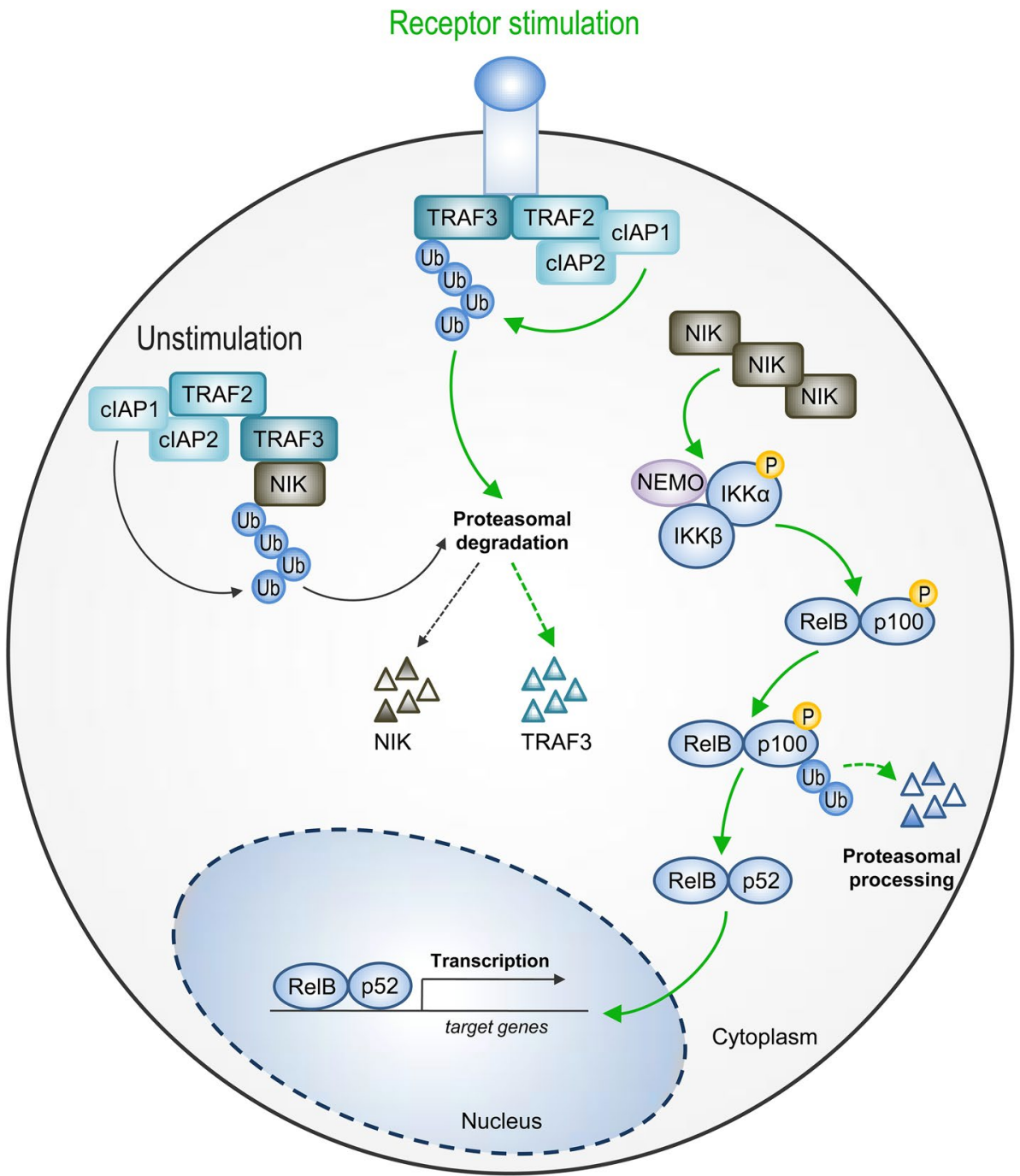


and LPS in the activation of p100 to p52 functional subunit processing at the ribosome level (Mordmüller et al. 2003).

The common regulation of canonical and non-canonical NF- $\mathrm{KB}$ activation is orchestrated by TRAF adaptor molecules that may positively or negatively regulate both signaling pathways. Among these, TRAF3 is critical for virus-induced IRF3-IRF7 activation and controls the noncanonical NF- $\mathrm{KB}$ pathway. Under resting conditions, TRAF3 associates with NIK and mediates NIK ubiquitination and proteasomal degradation. Upon stimulation, TRAF3 is degraded via the activity of TRAF2 and the cellular inhibitor of apoptosis (cIAP). Thus, NIK is stabilized (Oeckinghaus et al. 2011). The importance of TRAF3 in non-canonical NF- $\mathrm{KB}$ signaling has been demonstrated on TRAF3-deficient mouse embryonic fibroblasts and B cells, which show NIK accumulation together with constitutive $\mathrm{p} 100$ processing (He et al. 2006). Similarly, in B cells, TRAF2 or TRAF3 deficiency resulted in NIK accumulation and constitutive activation of the non-canonical NF- $\mathrm{kB}$ signaling pathway. TRAF1 may enhance the activity of the cIAP-TRAF2-TRAF3 E3 ubiquitin ligase complex, which drives destruction of NIK. Additionally, ablation of two cIAP1 and cIAP2 proteins, which are functionally redundant, results in NIK stabilization and the activation of the non-canonical NF- $\mathrm{\kappa B}$ signaling pathway (Yang and Sun 2015). However, both IKK $\alpha$ and the TRAF family member-associated NF- $\kappa \mathrm{B}$ activator-binding kinase 1 phosphorylate NIK leading to the induction of its degradation. As a result, the non-canonical NF- $\mathrm{KB}$ signaling is abolished (Vallabhapurapu et al. 2013).

Functional cooperation between canonical and noncanonical NF- $\kappa \mathrm{B}$ signaling pathways is mediated by NF- $\mathrm{\kappa B}$ dimerization. However, the mechanism of NF- $\mathrm{kB}$ subunit dimerization may also mediate negative crosstalk between both pathways. An example of such regulation is the ability of RelA to repress RelB in TNF- $\alpha$-stimulated cells. As a consequence of RelB binding by RelA, the DNA binding activity of RelB is abrogated. Nevertheless, upon independent activation of RelA and RelB by LT- $\beta$ R and TNF- $\alpha$, the synergistic induction of chromatin remodeling within the granulocyte-macrophage colony-stimulating factor promoter can be observed (Sun 2012). Non-canonical NF-KB signaling suppresses the binding of RelA to the ifnb gene promoter and appears to regulate histone modification in this promoter (Jin et al. 2014). IKK $\alpha$ may switch off the canonical NF- $\kappa B$ pathway. This strategy leads to the resolution of inflammation and prevents tissue injury. At the same time, IKK $\alpha$ can regulate adaptive immunity via the noncanonical pathway. Therefore, inhibition of IKK $\alpha$ may be utilized as a therapeutic approach (Lawrence 2009). Another $\mathrm{NF}-\kappa \mathrm{B}$ signaling regulatory strategy is represented by A20, an ubiquitin-editing enzyme, which is involved in switching from canonical to non-canonical NF- $\mathrm{KB}$ signaling upon LT- $\beta$ R stimulation by binding of cIAP1, which results in dissociation of TRAF2/TRAF3 interaction (Yamaguchi et al. 2013). Also, Akt kinase, which activates canonical NF- $\mathrm{KB}$ signaling, promotes $\mathrm{p} 100$ processing leading to $\mathrm{p} 52$ generation (Gustin et al. 2006).

$\mathrm{NF}-\mathrm{kB}$ is activated by viruses which are linked to malignant cell transformation due to their anti-apoptotic effect on host cells. Pathogens belonging to oncogenic viruses persistently activate the non-canonical NF- $\mathrm{\kappa B}$ pathway due to the presence of viral factors that help establish the activated state of NF- $\kappa \mathrm{B}$. A great example of a highly specialized $\mathrm{NF}-\kappa \mathrm{B}$ activating virus is human immunodeficiency virus type 1 (HIV-1). HIV-1 triggers the two (canonical and noncanonical) NF- $\mathrm{kB}$ signaling pathways via the Vpr protein, which enhances the phosphorylation of IKK $\alpha / \beta$ (Liu et al. 2013). Similarly, the Tax protein expressed by human T-cell leukemia virus type 1 stimulates canonical and non-canonical NF-кB pathways, but requires both IKK $\alpha$ and IKK $\gamma$ subunits to exert this effect. Kaposi's sarcoma-associated herpesvirus, in turn, encodes an anti-apoptotic protein, viral FLICE (Caspase-8) inhibitory protein (FLIP), a homolog of the cellular FLIP, which activates canonical and noncanonical NF- $\kappa B$ signaling via IKK $\gamma$. Another example of an NF- $\mathrm{KB}$ oncogenic activator is latent membrane protein 1 encoded by Epstein-Barr virus, which activates NF- $\mathrm{\kappa B}$ signaling via TRAF molecules. Among viral products that activate both non-canonical and canonical NF- $\mathrm{KB}$ signaling is oncoprotein Tio encoded by herpesvirus ateles (Sun 2011; Zhao et al. 2015).

Although activation of non-canonical NF- $\mathrm{KB}$ signaling by certain viruses is attributed to their anti-apoptotic effect and tumorigenesis, other data reveal that the non-canonical NF-kB pathway controls the induction of type I IFNs. This finding demonstrates the unexpected role of the non-canonical NF- $\kappa$ B activation pathway in antiviral innate immunity (Jin et al. 2014). Meanwhile, non-oncogenic viruses (both RNA and DNA) can influence the components of noncanonical NF- $\mathrm{KB}$ signaling, which consequently leads to modulation of antiviral immune response (Fig. 2).

\section{RNA Viruses}

\section{Orthomyxoviridae}

Influenza A virus (IAV), a single-stranded (ss), negative sense-(-)RNA orthomyxovirus of Influenzavirus A genus, is known for its antigenic drift and is well adapted to its hosts due to the multiple interactions between viral, host and environmental factors (Yoo et al. 2018). The role of NF- $\mathrm{KB}$ during IAV infection of upper and lower respiratory tract lung epithelial cells remains unclear. Nevertheless, it is assumed that it is the viral genotype that determines susceptibility to 


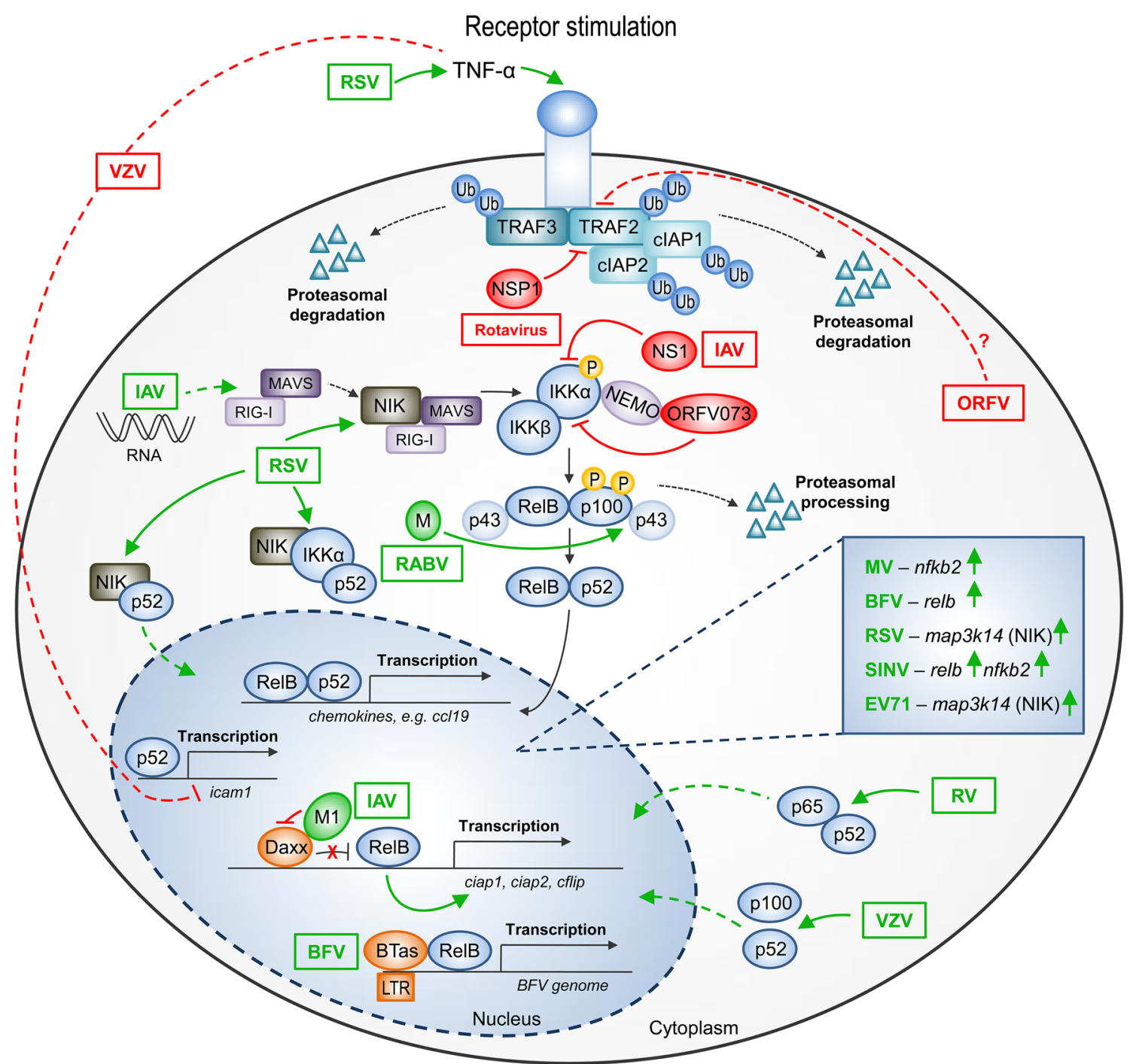

Fig. 2 Influence of non-oncogenic viruses on the components of non-canonical NF- $\kappa \mathrm{B}$ signaling. A schematic representation of the non-canonical NF- $\mathrm{KB}$ signaling pathway and its modulation by nononcogenic viruses. Activation of the major components of the non- canonical NF-кB pathway by viruses is indicated by pointing green arrows, whereas inhibition - by red blunt arrows. The effects of viral pathogens on the non-canonical NF- $\mathrm{KB}$ signaling are described in the text

and in vivo. NS1-IKK $\alpha$ interaction inhibits NIK-induced p100 processing, and, as a consequence, non-canonical NF- $\kappa B$ signaling (Gao et al. 2012).

Halder et al. (2013) showed that RelB transcript level remains unchanged during IAV infection. However, RelBregulated survival ciap1, ciap2, and cflip genes undergo activation by IAV matrix protein 1 (M1), which binds death domain-associated protein 6 (Daxx) (Halder et al. 2013). Daxx, in turn, is a transcriptional repressor of RelB, which binds RelB and is involved in epigenetic silencing of RelB-regulated genes. Daxx acts via recruitment of DNA methyltransferase 1 to promoters of target genes and can control genes responsible for apoptosis regulation (Croxton et al. 2006; Puto and Reed 2008). As a result of M1-Daxx 
interaction, Daxx is not able to bind to ciap1, ciap2, and cflip gene promoters. Therefore, survival genes are upregulated (Halder et al. 2013).

\section{Paramyxoviridae}

Respiratory syncytial virus (RSV) is a member of the Pneumovirus genus and Pneumovirinae subfamily of (-)ssRNA paramyxoviruses. In humans, RSV is regarded as a major causative agent of severe lower respiratory tract infection, which leads to lung immune cell infiltration (Canedo-Marroquín et al. 2017).

For in vitro studies of RSV infection, A549 lung-derived human epithelial cell line can be used (Choudhary et al. 2005). In this model of RSV infection, an increase in both NIK mRNA and protein expression, as well as NIK kinase activity were observed. In RSV-infected cells, activation of non-canonical NF- $\mathrm{KB}$ signaling precedes stimulation of more influential canonical NF- $\mathrm{KB}$ signaling (Choudhary et al. 2005). The induction of non-canonical NF-KB signaling during RSV infection is mediated by TNF- $\alpha$, which activates NF-kB2 and RelB (Dave et al. 2014). In RSV-infected cells, the formation of the NIK/IKK $\alpha / \mathrm{p} 52$ complex and NIK/ p52 nuclear translocation can be detected. Additionally, NIK knockdown via siRNA prevents RSV-induced p100 processing in the proteasome, together with the abrogation of activation of NF-кB-regulated genes (Choudhary et al. 2005).

As mentioned above, canonical NF- $\mathrm{kB}$ signaling follows the non-canonical pathway during RSV infection. However, RelA, a canonical NF- $\kappa B$ component, is partially activated by RSV via the NIK/IKK $\alpha$ complex. Upon RSV infection, NIK/IKK $\alpha$ interacts with MAVS, an adaptor protein of RIG-I. The NIK/IKK $\alpha$ complex, in turn, triggers RelA release from p100 in the cell cytoplasm. RIG-I silencing leads to the inhibition of basal $\mathrm{p} 100$ processing and $\mathrm{p} 100$ processing activated by RSV. NIK-IKK $\alpha$ activation may inhibit inflammatory chemokine secretion. These findings lead to the conclusion that NIK-IKK $\alpha$ signaling may be considered a therapeutic target in RSV infections (Liu et al. 2008).

Other studies on RSV infection show the role of NF-кB2 in the induction of antiviral gene expression. Among antiviral cytokines, IL-15 plays a prominent role in host antiviral defense. In $n f-k b 2^{-/-}$bone marrow derived macrophages (BMDMs) infected with RSV, induction of IL-15 gene transcription is abrogated. Additionally, BMDM treatment with polyinosinic:polycytidylic acid [poly(I:C)] via TLR3 results in binding of NF- $\kappa \mathrm{B} 2$ to the Sp1 promoter to induce transcription, which depends on NF- $\mathrm{BB}$ signaling components, including NF- $\kappa \mathrm{B} 2$. NF- $\kappa \mathrm{B} 2 \mathrm{p} 52$, in turn, is considered a target for IKK $\varepsilon$, thus playing a role in antiviral immunity (Doyle et al. 2013).

Another member of the Paramyxoviridae family, the measles virus (MV), belonging to genus Morbillivirus, is a pathogen with the only reservoir in humans, which infects different cell types (Da Fontoura Budaszewski and von Messling 2016; Moss 2017). The study of non-canonical NF- $\kappa B$ signaling in MV Edmonston strain-infected human peripheral blood mononuclear cells has led to observations that both mRNA and protein levels of NF- $\mathrm{kB} 2$ p52 are upregulated in virus-infected cells. In general, p52/p52 form homodimers, which exert a repressive effect on transcription; however, MV induces upregulation of B cell lymphoma protein-3, which may bind $\mathrm{p} 52$ homodimers resulting in the counteraction of transcription repression induced by $\mathrm{p} 52 /$ p52 homodimers (Bolt et al. 2002).

\section{Picornaviridae}

Human enterovirus 71 (EV71) belonging to genus Enterovirus, is a positive sense-(+)ssRNA virus within the Picornaviridae family and a causative agent of hand, foot, and mouth disease. EV1 infection results in a febrile and highly contagious illness that may lead to neurological complications (Cox et al. 2017; Yi et al. 2017). During the early and late hours post-infection by a rhabdomyosarcoma cell line with EV71, enhanced gene expression of mitogen-activated protein kinase (MAPK) signaling pathway components, such as NIK, a key regulator of non-canonical NF-KB signaling, can be detected. This observation leads to the conclusion that the activation of MAPK signaling upon EV71 infection may be responsible for inflammatory cytokine secretion, as well as apoptosis of EV71-infected cells (Shi et al. 2013).

Another representative of the genus Enterovirus, Rhinovirus (RV), which is known as the cause of the mild common cold, can also be detected in patients with pneumonia and other respiratory tract infections (To et al. 2017). RV infection stimulates the activation of NF- $\mathrm{KB}$ transcription factors and cytokine production (Zhu et al. 1996, 1997). In particular, in A549 cells infected with the RV14 serotype, the induction of the transcriptional activation of NF- $\kappa B$ family proteins, including $\mathrm{p} 52$, but not RelB, can be observed. Therefore, it is likely that p52-p65 heterodimers are activated by RV; yet, transcription of particular genes requires additional cofactors (Zhu et al. 1996).

\section{Reoviridae}

Rotavirus is a genus that encompasses double-stranded (ds) RNA viruses within the Reoviridae family and is a most common causative agent of severe infantile gastroenteritis (Burnett et al. 2018; Mokomane et al. 2018). The rotavirus genome is composed of 11 segments, which encode six structural and non-structural proteins, whose number depends on the virus strain (Hu et al. 2012). Among rotavirus-encoded non-structural proteins, NSP1 interacts with TRAF2 resulting in its degradation and inhibition of 
IFN- $\beta$-mediated p52 activation. This inhibition of noncanonical NF- $\mathrm{KB}$ signaling and cytokine response may be a viral strategy for evading immune effector mechanisms (Bagchi et al. 2013).

\section{Retroviridae}

Bovine foamy virus (BFV), known as bovine syncytial virus, belonging to the genus Spumavirus and Spumaretrovirinae subfamily of Retroviridae, an ss(+)RNA virus that infects its host with no association with clinical outcome (Hechler et al. 2012). BFV utilizes host signaling pathways to enhance its replication in host cells. This ability was demonstrated in vitro by Wang et al. (2010b) who reported that BFV activates non-canonical NF- $\mathrm{KB}$ signaling, including IKK $\alpha$ and p100, which undergo processing by NF- $\mathrm{KB}$ transactivator BTas. This activation may increase viral transcription (Wang et al. 2010b).

BFV has also been shown to interact with RelB, which can bind to the BFV long terminal repeat (LTR) and interacts with RelB transactivator BTas in vitro and in vivo. In addition, relb gene expression is elevated in BFV-infected HeLa cells. Moreover, RelB, which enhances viral transcription in the nucleus, acts as a cotransactivator of BTas. The Rel homology domain is essential for RelB-BTas interaction. This process can be observed due to NF- $\mathrm{KB}$ activation via $\mathrm{BTas}$, whose transfection into cells results in increased RelB mRNA expression (Wang et al. 2010a).

\section{Rhabdoviridae}

Rabies virus (RABV), belonging to the Rhabdoviridae family and Lyssavirus genus, is an (-)ssRNA virus, which evades immune response by blocking cellular pathways activating transcription factors. The matrix (M) protein of RABV interacts with RelAp43, a splicing variant of RelA, and at the same time, a competitor protein of RelA in canonical and non-canonical NF- $\mathrm{KB}$ signaling. The non-canonical NF- $\kappa B$ activation pathway is affected by the RABV M protein due to the enhanced interaction between RelAp43 and two components of non-canonical NF- $\mathrm{KB}$ signaling: RelB and p100/p52 (Besson et al. 2017; Fooks et al. 2017; Luco et al. 2012).

\section{Togaviridae}

Sindbis virus (SINV), an (+)ssRNA virus belonging to genus Alphavirus of the Togaviridae family, is transmitted by mosquitoes and may cause persisting musculoskeletal symptoms in humans (Adouchief et al. 2016). Alphaviruses have developed efficient strategies which affect the antiviral response of host cells, including IFN-mediated gene expression (Fros and Pijlman 2016). Nenasheva et al.
(2015) studied the response of human embryonic kidney cells to SINV infection. SINV infection resulted in upregulation of relb and $n f-k b 2$ gene expression, and others, such as interferon genes, which may play a role in innate immunity (Nenasheva et al. 2015).

\section{DNA Viruses}

\section{Herpesviridae}

Varicella zoster virus (VZV), also known as human herpesvirus type 3, is a dsDNA virus belonging to genus Varicellovirus and the Alphaherpesvirinae subfamily of the family Herpesviridae. VZV is a causative agent of highly contagious varicella (chickenpox) (Bollaerts et al. 2017; Sauerbrei 2016). In vitro studies on VZV pathogenesis have shown that in VZV-infected melanoma MeWo cell line and MRC5 human lung fibroblast cells, increased levels of nuclear p100 and p52 can be observed. Moreover, the inhibition of TNF- $\alpha$-induced recruitment of NF- $\mathrm{KB}$, including $\mathrm{p} 52$ to the icam 1 promoter during VZV infection has been detected in MeWo cells (El Mjiyad et al. 2007).

\section{Poxviridae}

Among DNA viruses, poxviruses are well-known for modulating host immune response and inhibiting canonical NF- $\kappa \mathrm{B}$ signaling at multiple levels (Brady and Bowie 2014). Orf virus (ORFV) belonging to the genus Parapoxvirus of the Chordopoxvirinae subfamily and Poxviridae family of large dsDNA viruses is a pathogen in sheep and goats, as well as a zoonotic agent, which can be used as an immunomodulating drug after inactivation (Bergqvist et al. 2017).

ORFV infection results in orf, a dermal disease manifested by contagious pustular dermatitis (Bergqvist et al. 2017; Spyrou and Valiakos 2015). Among ORFV-encoded immunomodulatory molecules, ORFV073 can inhibit IKK activation early on during the infection and interacts with NEMO, which is also involved in non-canonical NF- $\mathrm{BB}$ signaling. Therefore, it is assumed that ORFV may also affect TRAF2, which mediates both canonical and noncanonical NF- $\kappa B$ activation (Khatiwada et al. 2017). TRAF2 is also crucial for IFN-induced non-canonical NF- $\kappa B$ signaling (Yang et al. 2005, 2008). On the other hand, TRAF2 promotes other poxvirus, vaccinia virus replication; therefore, it may act as a proviral factor (Haga et al. 2014). Therefore, the evaluation of the impact of ORFV and other poxviruses on non-canonical NF- $\mathrm{KB}$ signaling needs further investigation. 


\section{Conclusions and Perspectives}

Viruses are masters of immune response modulation. Therefore, we can assume that there are still plenty of mechanisms for subverting host antiviral immune responses that remain elusive. From the time when particular viruses were linked to apoptosis inhibition and tumorigenesis, research efforts on the role of non-canonical NF- $\mathrm{KB}$ signaling in viral infection have been focused on oncogenic viruses. Although several datasets present the involvement of non-canonical NF- $\mathrm{KB}$ signaling in non-oncogenic viral infections, the emerging role of non-canonical NF- $\mathrm{KB}$ activation in innate immunity suggests that new scope for the study of viral pathogenesis has been unravelled.

Acknowledgements This work was supported by Grant no. UMO2015/19/D/NZ6/02873 from National Science Centre, Poland.

\section{Compliance with Ethical Standards}

Conflict of interest The authors declare that they have no conflict of interest.

Open Access This article is distributed under the terms of the Creative Commons Attribution 4.0 International License (http://creativeco mmons.org/licenses/by/4.0/), which permits unrestricted use, distribution, and reproduction in any medium, provided you give appropriate credit to the original author(s) and the source, provide a link to the Creative Commons license, and indicate if changes were made.

\section{References}

Adouchief S, Smura T, Sane J et al (2016) Sindbis virus as human pathogen-epidemiology, clinical picture and pathogenesis. Rev Med Virol 26:221-241

Bagchi P, Bhowmick R, Nandi S et al (2013) Rotavirus NSP1 inhibits interferon induced non-canonical NF- $\mathrm{KB}$ activation by interacting with TNF receptor associated factor 2. Virology 444:41-44

Bergqvist C, Kurban M, Abbas O (2017) Orf virus infection. Rev Med Virol. https://doi.org/10.1002/rmv.1932

Besson B, Sonthonnax F, Duchateau M et al (2017) Regulation of NF- $\kappa \mathrm{B}$ by the p105-ABIN2-TPL2 complex and RelAp43 during rabies virus infection. PLoS Pathog 13:e1006697

Biswas SK, Lewis CE (2010) NF- $\kappa$ B as a central regulator of macrophage function in tumors. J Leukoc Biol 88:877-884

Bollaerts K, Riera-Montes M, Heininger U et al (2017) A systematic review of varicella seroprevalence in European countries before universal childhood immunization: deriving incidence from seroprevalence data. Epidemiol Infect 145:2666-2677

Bolt G, Berg K, Blixenkrone-Møller M (2002) Measles virus-induced modulation of host-cell gene expression. J Gen Virol 83(Pt 5):1157-1165

Brady G, Bowie AG (2014) Innate immune activation of NFkB and its antagonism by poxviruses. Cytokine Growth Factor Rev 25:611-620

Burnett E, Parashar U, Tate J (2018) Rotavirus vaccines: effectiveness, safety, and future directions. Paediatr Drugs 20:223-233
Canedo-Marroquín G, Acevedo-Acevedo O, Rey-Jurado E et al (2017) Modulation of host immunity by human respiratory syncytial virus virulence factors: a synergic inhibition of both innate and adaptive immunity. Front Cell Infect Microbiol 7:367

Choudhary S, Boldogh S, Garofalo R et al (2005) Respiratory syncytial virus influences NF- $\mathrm{KB}$-dependent gene expression through a novel pathway involving MAP3K14/NIK expression and nuclear complex formation with NF-кB2. J Virol 79:8948-8959

Cox JA, Hiscox JA, Solomon T et al (2017) Immunopathogenesis and virus-host interactions of enterovirus 71 in patients with hand, foot and mouth disease. Front Microbiol 8:2249

Croxton R, Puto LA, de Belle I et al (2006) Daxx represses expression of a subset of antiapoptotic genes regulated by nuclear factor- $\mathrm{\kappa B}$. Cancer Res 66:9026-9035

Da Fontoura Budaszewski R, Von Messling V (2016) Morbillivirus experimental animal models: measles virus pathogenesis insights from canine distemper virus. Viruses 8 pii:E274

Dam S, Kracht M, Pleschka S et al (2016) The influenza A virus genotype determines the antiviral function of NF- $\kappa B$. J Virol 90:7980-7990

Dave KA, Norris EL, Bukreyev AA et al (2014) A comprehensive proteomic view of responses of A549 type II alveolar epithelial cells to human respiratory syncytial virus infection. Mol Cell Proteom 13:3250-3269

Dejardin E (2006) The alternative NF-кB pathway from biochemistry to biology: pitfalls and promises for future drug development. Biochem Pharmacol 72:1161-1179

Doyle SL, Shirey KA, McGettrick AF et al (2013) Nuclear factor $\kappa B 2$ p52 protein has a role in antiviral immunity through IкB kinase $\varepsilon$-dependent induction of Sp1 protein and interleukin 15. J Biol Chem 288:25066-25075

El Mjiyad N, Bontems S, Gloire G et al (2007) Varicella-zoster virus modulates NF- $\kappa \mathrm{B}$ recruitment on selected cellular promoters. J Virol 81:13092-13104

Espinosa L, Bigas A, Mulero MC (2011) Alternative nuclear functions for NF- $\kappa$ B family members. Am J Cancer Res 1:446-459

Fooks AR, Cliquet F, Finke S et al (2017) Rabies. Nat Rev Dis Primers 3:17091

Freaney JE, Kim R, Mandhana R et al (2013) Extensive cooperation of immune master regulators IRF3 and NFKB in RNA Pol II recruitment and pause release in human innate antiviral transcription. Cell Rep 4:959-973

Fros JJ, Pijlman GP (2016) Alphavirus infection: host cell shut-off and inhibition of antiviral responses. Viruses 8 pii:E166

Gao S, Song L, Li J et al (2012) Influenza A virus-encoded NS1 virulence factor protein inhibits innate immune response by targeting IKK. Cell Microbiol 14:1849-1866

Gustin JA, Korgaonkar CK, Pincheira R et al (2006) Akt regulates basal and induced processing of NF-kB2 (p100) to p52. J Biol Chem 281:16473-16481

Haga IR, Pechenick Jowers T, Griffiths SJ et al (2014) TRAF2 facilitates vaccinia virus replication by promoting rapid virus entry. $\mathrm{J}$ Virol 88:3664-3677

Halder UC, Bhowmick R, Roy Mukherjee T et al (2013) Phosphorylation drives an apoptotic protein to activate antiapoptotic genes: paradigm of influenza A matrix 1 protein function. J Biol Chem 288:14554-14568

Hayden MS, Ghosh S (2012) NF- $\kappa B$, the first quarter century: remarkable progress and outstanding questions. Genes Dev 26:203-234

He JQ, Zarnegar B, Oganesyan G et al (2006) Rescue of TRAF3-null mice by p100 NF-кB deficiency. J Exp Med 203:2413-2418

Hechler T, Materniak M, Kehl T et al (2012) Complete genome sequences of two novel European clade bovine foamy viruses from Germany and Poland. J Virol 86:10905-10906

Hoesel B, Schmid JA (2013) The complexity of NF- $\kappa$ B signaling in inflammation and cancer. Mol Cancer 12:86 
Hu L, Crawford SE, Hyser JM et al (2012) Rotavirus non-structural proteins: structure and function. Curr Opin Virol 2:380-388

Jin J, Hu H, Li HS et al (2014) Noncanonical NF-kB pathway controls the production of type I interferons in antiviral innate immunity. Immunity 40:342-354

Khatiwada S, Delhon G, Nagendraprabhu P et al (2017) A parapoxviral virion protein inhibits NF- $\mathrm{KB}$ signaling early in infection. PLoS Pathog 13:e1006561

Kim JY, Morgan M, Kim DG et al (2011) TNF $\alpha$ induced noncanonical NF- $\kappa B$ activation is attenuated by RIP1 through stabilization of TRAF2. J Cell Sci 124(Pt 4):647-656

Krug RM (2015) Functions of the influenza A virus NS1 protein in antiviral defense. Curr Opin Virol 12:1-6

Lawrence T (2009) The nuclear factor NF-кB pathway in inflammation. Cold Spring Harb Perspect Biol 1:a001651

Liu P, Li K, Garofalo RP et al (2008) Respiratory syncytial virus induces RelA release from cytoplasmic 100-kDa NF-кB2 complexes via a novel retinoic acid-inducible gene-I.NF- $\mathrm{KB}$-inducing kinase signaling pathway. J Biol Chem 283:23169-23178

Liu R, Tan J, Lin Y et al (2013) HIV-1 Vpr activates both canonical and non-canonical NF- $\mathrm{BB}$ pathway by enhancing the phosphorylation of IKK $\alpha / \beta$. Virology 439:47-56

Luco S, Delmas O, Vidalain PO et al (2012) RelAp43, a member of the NF- $\kappa \mathrm{B}$ family involved in innate immune response against Lyssavirus infection. PLoS Pathog 8:e1003060

Mokomane M, Kasvosve I, de Melo E et al (2018) The global problem of childhood diarrhoeal diseases: emerging strategies in prevention and management. Ther Adv Infect Dis 5:29-43

Mordmüller B, Krappmann D, Esen M et al (2003) Lymphotoxin and lipopolysaccharide induce NF- $\mathrm{kB}-\mathrm{p} 52$ generation by a co-translational mechanism. EMBO Rep 4:82-87

Moss WJ (2017) Measles. Lancet 390:2490-2502

Nenasheva VV, Kovaleva GV, Uryvaev LV et al (2015) Enhanced expression of trim 14 gene suppressed Sindbis virus reproduction and modulated the transcription of a large number of genes of innate immunity. Immunol Res 62:255-262

Oeckinghaus A, Ghosh S (2009) The NF- $\mathrm{B}$ family of transcription factors and its regulation. Cold Spring Harb Perspect Biol 1:a000034

Oeckinghaus A, Hayden MS, Ghosh S (2011) Crosstalk in NF-кB signaling pathways. Nat Immunol 12:695-708

Olagnier D, Hiscott J (2012) Breaking the barrier: membrane fusion triggers innate antiviral immunity. Nat Immunol 13:713-715

Puto LA, Reed JC (2008) Daxx represses RelB target promoters via DNA methyltransferase recruitment and DNA hypermethylation. Genes Dev 22:998-1010

Rajsbaum R, García-Sastre A (2013) Viral evasion mechanisms of early antiviral response involving regulation of ubiquitin pathways. Trends Microbiol 21:421-429

Rückle A, Haasbach E, Julkunen I et al (2012) The NS1 protein of influenza A virus blocks RIG-I-mediated activation of the noncanonical NF- $\mathrm{BB}$ pathway and p52/RelB-dependent gene expression in lung epithelial cells. J Virol 86:10211-10217
Sauerbrei A (2016) Diagnosis, antiviral therapy, and prophylaxis of varicella-zoster virus infections. Eur J Clin Microbiol Infect Dis 35:723-734

Shi W, Hou X, Li X et al (2013) Differential gene expressions of the MAPK signaling pathway in enterovirus 71-infected rhabdomyosarcoma cells. Braz J Infect Dis 17:410-417

Shih VF, Tsui R, Caldwell A et al (2011) A single NFkB system for both canonical and non-canonical signaling. Cell Res 21:86-102

Spyrou V, Valiakos G (2015) Orf virus infection in sheep or goats. Vet Microbiol 181:178-182

Sun SC (2011) Non-canonical NF-кB signaling pathway. Cell Res 21:71-85

Sun SC (2012) The noncanonical NF-кB pathway. Immunol Rev 246:125-140

To KKW, Yip CCY, Yuen KY (2017) Rhinovirus-from bench to bedside. J Formos Med Assoc 116:496-504

Vallabhapurapu SD, Pagolu KR, Vallabhapurapu S (2013) Regulation of the alternative NF- $\kappa B$ pathway and its role in cancer. J Cancer Sci Ther 5:e122

Wang J, Tan J, Guo H et al (2010a) Bovine foamy virus transactivator BTas interacts with cellular RelB to enhance viral transcription. J Virol 84:11888-11897

Wang J, Tan J, Zhang X et al (2010b) BFV activates the NF-kB pathway through its transactivator (BTas) to enhance viral transcription. Virology 400:215-223

Yamaguchi N, Oyama M, Kozuka-Hata H et al (2013) Involvement of A20 in the molecular switch that activates the non-canonical NF-кB pathway. Sci Rep 3:2568

Yang XD, Sun SC (2015) Targeting signaling factors for degradation, an emerging mechanism for TRAF functions. Immunol Rev 266:56-71

Yang CH, Murti A, Pfeffer LM (2005) Interferon induces NF-кBinducing kinase/tumor necrosis factor receptor-associated factordependent NF- $\kappa \mathrm{B}$ activation to promote cell survival. J Biol Chem 280:31530-31536

Yang CH, Murti A, Pfeffer SR et al (2008) The role of TRAF2 binding to the type I interferon receptor in alternative NFkB activation and antiviral response. J Biol Chem 283:14309-14316

Yi EJ, Shin YJ, Kim JH et al (2017) Enterovirus 71 infection and vaccines. Clin Exp Vaccine Res 6:4-14

Yoo SJ, Kwon T, Lyoo YS (2018) Challenges of influenza A viruses in humans and animals and current animal vaccines as an effective control measure. Clin Exp Vaccine Res 7:1-15

Zhao J, He S, Minassian A et al (2015) Recent advances on viral manipulation of NF- $\mathrm{\kappa B}$ signaling pathway. Curr Opin Virol 15:103-111

Zhu Z, Tang W, Ray A et al (1996) Rhinovirus stimulation of interleukin-6 in vivo and in vitro. Evidence for nuclear factor $\kappa B$-dependent transcriptional activation. J Clin Invest 97:421-430

Zhu Z, Tang W, Gwaltney JM Jr et al (1997) Rhinovirus stimulation of interleukin- 8 in vivo and in vitro: role of NF- $\kappa B$. Am J Physiol 273(Pt 1):L814-L824 